\title{
Por uma clínica dos transtornos da conduta sexual em harmonia com a realidade sociocultural dos pacientes
}

Carlos Alberto Dias*

Trata-se de um trabalho opinativo realizado segundo o método de pesquisa bibliográfica. Seu objetivo é chamar a atenção dos profissionais que trabalham com indivíduos portadores de distúrbios funcionais da sexualidade, para uma realidade que ultrapassa a mera observação do indivíduo enquanto paciente.

Partindo de uma análise sociocultural em que se circunscreve nossa prática clínica, o autor faz um breve histórico de como a questão vem sendo estudada no campo da psicologia. Considerando insuficientes as teorias psicológicas que abordam a questão, aponta para a necessidade de buscarmos na sociologia e na etnologia um saber que complemente nosso saber possibilitando uma melhor atuação sobre o fenômeno, seja enquanto psicoterapeutas, seja enquanto terapeutas sexuais.

* Psicólogo. Professor da Universidade Vale do Rio Doce-MG. Mestrado (D.E.A.) em Psicopatologia pela Université de Picardie Jules Verne - França.

Recebido em 05.03 .98

Aprovado em 15.03.98 


\section{Um contexto sociocultural}

A média de idade da população brasileira tem se elevado significativamente nas duas últimas décadas. O país com população considerada jovem, anteriormente, iniciou um processo de envelhecimento, prevalecendo hoje cidadãos com idade entre 20 a 59 anos. A paulatina redução da taxa de fecundidade e a elevação da esperança de vida nos obrigam a atentarmos para os problemas característicos desse grupo, no que diz respeito ao comportamento sexual.

Atualmente apenas $10 \%$ da população tem acesso ao ensino de $2^{\circ}$ grau e $4,4 \%$ ao curso superior. Dos $85,6 \%$ restantes, muitos não ultrapassam o $1^{\circ}$ ano e a maioria não conclui a $8^{\mathrm{a}}$ série do $1^{\circ}$ Grau (IBGE, 1994).

Para uma população de baixo nível cultural e cada vez mais envelhecida, resta uma atividade profissional de elevado desgaste físico e mental, constituindo-se a maioria em operários. As famílias desses indivíduos aglomeram-se em bairros com precárias condições de higiene, num ambiente em que a aprendizagem relacional é mal estruturada gerando pessoas desinformadas.

O precário acesso aos benefícios produzidos pelos avanços científicos desestimula a busca de um saber atualizado, favorecendo a disseminação de idéias retrógradas e estereotipadas. O saber que mais se aproxima de seu mundo de indagação é o saber religioso. Este de alguma forma "responde" a seus munieros questionamentos e se encontra ao alcance de suas possibilidades. Assim aos cidadãos parece mais viável seguir obstinadamente os valores e doutrinas difundidas pelas Instituições Religiosas.

Como maior cliente em potencial no Brasil, em análise e psicoterapia, temos indivíduos resultantes de: baixa escolaridade, reduzido acesso às informações científicas, carência de satisfação das necessidades básicas, despreparo das famílias na educação de seus membros e forte apego aos dogmas religiosos. Tudo isso nos leva a concluir que a saída que resta para os indivíduos é depositar as esperanças de um futuro melhor no misticismo religioso. Dessa forma, o indivíduo se submete às repressões sociais, valorizando o atendimento às normas mais que à satisfação de seus desejos. É nesse fenômeno que nossa estrutura social se assenta. Freud (1908, p. 192) ao falar da Moral Sexual Civilizada e Doença Nervosa Moderna afirma que "Nossa Civilização repousa... sobre a supressão dos instintos. Cada indivíduo renuncia a uma parte dos seus atributos.: uma parcela do seu 
sentimento de onipotência ou ainda das inclinações vingativas ou agressivas de sua personalidade .... Cada nova conquista foi sancionada pela religião, cada renúncia do indivíduo à satisfação instintual foi oferecida à divindade como um sacrifício, e foi declarado 'santo' o proveito assim obtido pela comunidade. Aquele que em conseqüência de sua constituição indomável não consegue concordar com a supressão do instinto, torna-se um 'criminoso', um 'outla w', diante da sociedade - a menos que sua posição social ou suas capacidades excepcionais the permitam impor-se como um grande homem, um 'herói"'.

Os avanços científicos no campo da medicina no tocante aos métodos anticonceptivos cuja proposta seja a de contribuir para com a vida sexual dos indivíduos, quando utilizados, são acompanhados de fortes sentimentos de culpa. Não podemos desconsiderar aqui o fato de que os ganhos secundários produzidos por essa prática, como possibilidade de acomodação e autopiedade, geram superproteção por parte de outros. Como consequencia, cresce a falta da necessidade de opor-se aos padrões estipulados pelo meio e a redução do ato reflexivo sobre o existir individual.

Ainda em relação ao exposto, está claro que a exacerbação do substituir o objetivo sexual por um social, mediante o processo de sublimação, tem na maioria das vezes efeitos perniciosos, pois no dizer de Freud (1908, p. 197) “... existe para a maioria das pessoas um limite além do qual suas constituições não podem atender às exigências da civilização. Aqueles que desejam ser mais nobres do que suas constituições lhes permitem, são vitimados pela neurose".

A formação cultural e religiosa da sociedade brasileira, bem como o subdesenvolvimento existente nos diversos níveis da estrutura social, reforçam em seus membros os "tabus" ligados à discussão sobre a prática da sexualidade. Apesar das aparências que são vendidas pelos meios de comunicação, somos uma sociedade puritana, que pouco se distancia do pensamento de Jeannière (1965, p. 177-178) quando diz que “... o sexual nada tem a ver com o ser-no-mundo. A escolha situar-se-á noutro ponto. As regras da união do homem com a mulher serão exteriores ao amor, assim como a toda a manifestação da sexualidade em que o amor se pudesse exprimir. O casamento é uma associação de interesses... econômicos e familiares... A religião dará sua contribuição para reforçar as proibições sexuais". A partir da observação do modo de conduta da sociedade brasileira, constata-se que as relações conjugais estão vinculadas as exigencias sociais e não aos desejos sexuais. Tal fenômeno tem como subproduto as dificuldades sexuais daqueles que se constituirão como pacientes psicoterápicos, e ainda, o surgimento 
de "deficiências" na conduta dos profissionais, pois também estes são atingidos pelo mesmo fenômeno.

Nos últimos anos, um maior número de pacientes, buscam auxílio psicológico para a solução de transtornos no campo da sexualidade. Infelizmente ao fazê-lo se encontram já próximos à cronificação da conduta indesejável, buscando no profissional soluções emergenciais. Quando estas não ocorrem, se recusam a prosseguir com o tratamento. E quando não, na continuação do processo através da "negligência" do profissional em deixar à margem as queixas no tocante ao desempenho sexual, são acompanhados por uma "desagregação familiar" que vai se constituindo em novo problema, que muitas vezes se torna irreversível.

A localização excessiva na etiologia dos transtornos sexuais, por despreparo do profissional, e a consequente redução da atenção à queixa inicial, leva o paciente em muitos dos casos a buscar de processos alternativos os quais por sua vez dão origem a novas condutas neurotizantes. Depois disso, ocorrendo um retorno ao profissional da psicologia, poderá o paciente apresentar ainda um quadro sintomático mais acentuado.

\section{Fundamentação}

Existem vários enfoques para a compreensão dos transtornos da conduta sexual humana. No clássico Tratado de Psiquiatria, de Henri Ey (1978), esse fenômeno é atribuído a conflitos decorrentes da fase do Complexo de Édipo. Dentro dessa perspectiva, Joêl Dor (1993) afirma que a frigidez é um sintoma da histeria feminina. Sendo a histérica incapaz de encontrar um objeto com poder de anular os rastros de imperfeições de que é portadora, é acompanhada por uma indecisão permanente, desde as coisas mais banais às mais significativas de sua vida. Esse sentimento de incompletude faz com que ela se lance na busca da perfeição, o que produz a convicção de uma permanente imperfeição. Na relação com seu parceiro, não lhe é possível o gozo, pois, só alguém que representa o falo (isto é, o parceiro de sua amiga, irmão ou um homem que lhe é inacessível) seria capaz de lhe proporcionar a realização de seu desejo. Quanto mais a histérica se queixa da insatisfação sexual, mais ofusca a segurança sexual do homem, confirmando a crença dela de que deve sempre esperar por algo melhor. Ainda à luz dessa compreensão, a impotência, por sua vez, ocorre a partir da percepção do histérico de que não é depositário do objeto fãlico desejado pela mulher. Ao ser chamado à prova de sua virilidade, torna-se impotente como se estivesse afirmando: não tenho o falo. Já a ejaculação precoce, é o testemunho de um peri- 
go imaginário quando do ato sexual com uma mulher. Para o histérico, apenas o que tem o domínio do falo pode dominar o gozo feminino. Como não se sente capaz disso, o gozo é entendido como uma ameaça à qual deve evitar. Durante o coito, ele se identifica com a mulher, capitulando diante daquele que tem o falo, e goza por ejaculação precoce, como imagina que faria a mulher diante do poder fálico.

Em síntese, como acentua Desprats-Péquinot (1992), a psicanálise defende a premissa de que os transtornos sexuais são a expressão de conflitos psicossexuais atrelados aos processos inconscientes e à fantasmática que governa a vida psíquica de cada indivíduo.

O behaviorismo, por sua vez, apoiando-se nos estudos do comportamento animal, fundamenta a psicossexualidade humana sobre os domínios biológicos e psicofisiológicos. Dentro dessa perspectiva, afirma que "o comportamento sexual adulto resulta da organização progressiva dos esquemas inatos de comportamento e hábitos adquiridos por aprendizagem, que concorrem para a realização da função de reprodução" (La Revue du Praticien, 13, 1977, p. 789, citada por Desprats-Péquignot, 1992). Sob esse ponto de vista, o transtorno da conduta sexual é compreendido como resultante de um condicionamento vivido pelo indivíduo.

Não negando as contribuições quer sejam da psicanálise, quer sejam do beliaviorismo, Cavalcanti \& Cavalcanti nos chamam a atenção para a integração de três elementos que não podem estar separados ao estudarmos cientificamente a questão dos distúrbios da conduta sexual: processo de aprendizagem, influências do contexto social, estruturação de uma autopercepção ao nível intrapsíquico a partir do vivido. Em seu livro, Tratamento Clínico das Inadequações Sexuais, Cavalcanti \& Cavalcanti (1992, p. 53) afirmam que "É preciso insistir na idéia de que o homem atua como um todo, e que o seu comportamento manifesto não é um simples produto mecânico de uma estimulação externa. A resposta encerra um conteúdo experiencial e cognitivo altamente subjetivo. O meio psicológico interno não é apenas um subproduto colateral da reação entre a estimulação externa e as potencialidades biológicas, não é um epifenômeno, mas algo atuante que entra na composição da resposta expressa. A relação entre o ser humano e o ambiente é portanto bidirecional e reciproca, em contínuo reajustamento através de circuitos de retroalimentação. Esta auto-regulação é que permite ao homem a capacidade de se auto-avaliar cognitivamente, em relação aos seus modelos de referência, e a partir daí obter reforços encobertos, positivos ou negativos, que lhe permitam selecionar os comportamentos internos e externos. O homem à medida que se 
comporta, é capaz de pensar sobre o seu próprio comportamento, de saber inclusive que está pensando e, nesta auto-observação, elaborar hipóteses sobre quais das suas condutas que serão positivas ou negativamente reforçadas". No tocante ao distúrbio da conduta sexual, os autores, de uma maneira sintética, explicam que "aprendemos no meio social a criar obstáculos à resposta fisiológica que é involuntariamente eliciada pela apresentação de um estímulo erótico. $O$ comportamento (sexual) disfuncional, portanto, é um comportamento aprendido"... (Cavalcanti \& Cavalcanti, p. 281).

Segundo Brenot (1994, p. 37-38), vários estudos em sexologia concorreram para que a posição psiquiátrica de considerarem os transtornos sexuais como provenientes de transtornos orgânicos se tornasse menos rígida, proporcionando o desenvolvimento de uma postura que relevasse uma compreensão multifatorial sobre as causas do problema. Entre esses estudos, se sobressaem os realizados por Balint (1966), propondo uma análise da relação do casal que apresenta comportamento sexual disfuncional; de Masters e Johnson, sobretudo com a publicação do Human Sexual Inadequacy (1970), que vêem os transtornos sexuais não com graves psicopatologias, mas como transtornos neuróticos e funcionais; e os de Abraham e Pasini (1974), que afirmam serem as transtornos sexuais provenientes da força das inibições neuróticas sobre os fatores instintivos.

As atuais condutas psicoterápicas no tratamento dos transtornos sexuais se orientam, basicamente, pela concepção psicanalítica ou pela orientação comportamentalista. Embora eficazes para a compreensão e tratamento de vários casos, outros não se adaptam às condições de uma análise ortodoxa, em razão da especificidade da demanda ou das características dos pacientes que vivem realidades socioculturais diversas, ultrapassando o campo meramente intrapsíquico ou da aprendizagem. Fazendo uma análise desses dois modelos no tratamento dos transtornos sexuais, Kaplan (1994, p. 182) afirma que "ambas são de imenso valor, mas nenhuma é completa quando for a única empregada”.

No decorrer de nossa atuação como psicólogo clínico, constatamos que os pacientes que apresentam quadro de transtornos sexuais sofrem dificuldades que não são exclusivas do campo da conduta sexual, estando relacionadas também a aspectos socioculturais que comprometem seriamente sua auto-imagem (Dias, 1996). Em função disso, percebemos que, para chegarmos ao cerne da problemática dos transtornos sexuais, se faz necessário conhecermos melhor sob que perspectivas a atividade sexual é concebida pelo grupo social dentro de um período histórico determinado, 
de que forma os papéis sociais são estruturados e repassados àqueles que deverão assumi-los, e quais fatores são concorrentes para a estruturação de uma personalidade em crise, no indivíduo, obrigando-o a buscar ajuda psicológica.

Os estudos de Foucault (1976) sobre a história da sexualidade no Ocidente, os de Pewzner (1996), denunciando a impregnação do sentimento de culpa que acompanha todos os atos do homem ocidental, os de Lorenzi-Cioldi (1988), acertando sobre as imagens representativas dos papéis masculino e feminino determinantes da divisão entre grupos dominados e dominantes, e os de Lipiansky (1992), que nos mostra que a auto-imagem da pessoa se constitui a partir das complexas interações mantidas com seu grupo sociocultural, lançam novas luzes sobre o caminho da pesquisa que pretendemos conduzir.

Foucault nos mostra que a prática da sexualidade sempre foi um tema de preocupação na sociedade ocidental. Após longo período de liberdade sexual, Iniciamos no século XVII uma era de repressão da sexualidade. A Igreja institui a confissão, na qual o indivíduo deveria transformar em discurso todos os seus pensamentos, desejos e ações, para proferi-lo no confessionário. Nessa prática, a emoção é transformada pelo próprio sujeito em descrição racional, para assim aprender a gerenciar esse dado existencial, colocando a vida sexual a serviço da mera continuidade da espécie. No século XVIII, o sexo se torna negócio político. Aqui não mais está em vigor o rigor de uma proibição da prática sexual, mas a necessidade de se colocar a sexualidade a serviço da utilidade pública. No centro dos problemas políticos e econômicos, o sexo passa a ser avaliado enquanto taxa de natalidade, idade propícia para o casamento, nascimentos legítimos e ilegítimos, precocidade e frequiência das relações sexuais, questões de fertilidade e esterilidade, práticas contraceptivas e outros. O sexo se tornou, então, um mecanismo a serviço do poder público. Ao final do século, a atividade sexual era regida por três códigos explícitos, além dos hábitos individuais: "o direito canônico, a pastoral cristã e a lei civil” (Foucault, 1976, p. 51). Apoiando-se na pedagogia e na medicina, a partir do século XIX, as velhas proibições começaram a ser usadas para perseguir os hábitos sexuais solitários das crianças, como, por exemplo, a masturbação. Ainda no século XVIII, foram lançadas as bases de controle (saber e poder) da sexualidade individual que se estendem até os dias atuais, como:

- Histerilização do corpo feminino - a mulher é vista como um corpo saturado de sexualidade, tornando suas condutas sexuais patológicas. 
- Pedagogização do sexo da criança - as orientações passam a ter como finalidade chamar a atenção para os perigos de uma sexualidade indevida ou precoce.

- Socialização das condutas de reprodução - o crescimento populacional passa a ser algo fiscalizado e controlado pelo poder público.

- Psiquiatrização do prazer perverso - estabelecimento de técnicas corretivas das condutas patológicas catalogadas ao longo do século XIX, centrando-se sobre a mulher histérica, a criança masturbadora, o casal malthusiano e o adulto perverso.

Em suma, Foucault observa que as relações entre os sexos deram lugar em todas as sociedades a um dispositivo de aliança: indústria do casamento, fixação e desenvolvimento de graus de parentesco, transmissão de nomes e bens de família. Pode-se dizer, a grosso modo, que uma nobre função da atividade sexual - busca do prazer - se perdeu ao longo de uma série de discursos em torno desses temas.

Sobre esse prisma, Pewzner nos mostra que a história do Ocidente e a história do cristianismo estão indissoluvelmente ligadas, mesmo nos momentos em que Igreja e Estado apresentaram interesses divergentes. Essa parceria impediu que a questão da sexualidade fosse vista por um ângulo eminentemente secularizado, contribuindo para que a idéia de pecado, que ocupa o centro do discurso do cristianismo, fosse difundida entre os membros de todas as sociedades cristãs. Como conseqüência, o sentimento de culpa se tornou um elemento constitutivo que permeia todas as relações sociais, podendo ser encontrado sem dificuldades no discurso do histérico e do psicótico. Nesse sentido, ela afirma que "o tema do pecado e do sentimento de culpa estão no centro da reflexão a respeito do tema do Mal no Ocidente; o discurso do doente mental se tornou o eco amplificado desta obsessão do mal interno gue consome o ser e fere sua relação com o sagrado" (Pewznzer, 1996, p. 46). Se a cultura brasileira é profundamente marcada pela presença do Cristianismo, a se os sujeitos que participam dessa sociedade, em sua grande maioria, tendem a buscar na religião respostas às questões existenciais que fazem parte de seu mundo relacional, não estaríamos nós, também imbuídos dessa idéia de culpabilidade? Precisamos considerar que o sentimento de culpa afeta o comportamento, mesmo daqueles indivíduos que não são considerados portadores de patologias psíquicas. 
Em nossa prática clínica, é possível constatar a presença do sentimento de culpa em inúmeros pacientes que nos procuram em função de suas dificuldades sexuais. $\mathrm{O}$ fato de alguém apresentar um comportamento sexual disfuncional não é suficiente para qualificá-lo como portador de um transtorno mental. Dessa forma, nos é evidente que o sentimento de culpa pode ser encontrado não só no discurso do doente mental, mas também no discurso do cidadão comum.

Lorenzi-Cioldi afirma que em nossas sociedades existe uma determinação de modelos de identidade, nos quais os papéis masculino e feminino são claramente delimitados. Acentua que o papel masculino é marcadamente instrumental, caracterizado pela autonomia, independência, sentimento de controle total sobre o meio ambiente e, ainda, pelo desenvolvimento das habilidades voltadas à competição. Nesse caso, toda relação é mantida como uma maneira de se atingir um resultado. Já o modelo feminino, predominantemente expressivo, é caracterizado pela busca de ligações afetivas, pelo desejo de estabelecimento de comunicação com o outro e a preocupação constante com a expressão de sentimentos pessoais. Nesse caso, os objetivos da relação estão contidos na relação em si mesma, e não em função de objetivos exteriores. Tais características afetam profundamente a prática da sexualidade, dadas as dificuldades em se estabelecer uma comunicação íntima a partir de objetivos convergentes. Segundo Lorenzi-Cioldi, "o homem típico é concebido em termos de assertividade, de atividade, de independência, de objetividade, de racionalidade e de competência, enquanto gue a mulher típica é, antes de tudo, passiva, emotiva, submissa e sensível às relações com os outros" (Cioldi, p. 45).

A questão dos transtornos da conduta sexual passa, necessariamente, pela questão do papel sexual vivenciado pelo homem e pela mulher, pois, paralelamente à construção da identidade social, existe também a construção de uma identidade sexual que determina de que maneira homem e mulher devem se posicionar um diante do outro para a realização do ato sexual. Nesse encontro, um dos elementos se torna para o outro o critério de confirmação da imagem que ele tem de si mesmo, em que se configura a possibilidade de sucesso ou fracasso. No tocante à identidade social, Lipiansky nos diz que "a identidade social designa, pois, a representação de si mesmo, que o sujeito procura construir e divulgar nas interações em que é parte integrante, representação esta que exige gue o sujeito seja reconhecido a certificado pelo outro, sendo essa identidade elaborada constantemente a partir dos modelos culturais e sociais" (Lipianski, p. 188). No que diz respeito à 
construção da identidade sexual, o autor nos diz ainda que "a identidade sexual não resulta apenas do sexo anatômico; ela se desenvolve também a partir das identificações da primeira infância e, notadamente, daquelas que se constroem em torno do complexo de Édipo. (...) Ao mesmo tempo, a identidade sexual se apóia, ainda, sobre os modelos de feminilidade e de virilidade propostas pela cultura" (Lipianski, p. 27).

\section{Conclusão}

É fato que os transtornos sexuais têm sido mais profundamente estudados e valorizados, dentro de uma perspectiva psicanalítica ou comportamental. Porém a partir do exposto, se nos atermos especificamente dentro desses dois limites, estaremos desvinculando nossa prática clínica da realidade vivida pelos pacientes. São inúmeras as forças que interagem na construção de modelos de sexualidade condicionando o indivíduo tanto no nível da representação quanto de sua prática sexual.

Estreitarmos nosso horizonte de compreensão dos transtornos sexuais, torna reduzido o sucesso nesse campo, visto que os clientes buscam psicólogos para tratamentos, e estes muitas vezes se mostram despreparados para fornecer o serviço. Sob esse prisma, Kusnetzoff (1987) afirma que "lamentavelmente, nossas faculdades de Medicina não contam, até agora, com programas de treinamento em Sexologia para médicos, isso faz com que, quando consultados, escondam sua ignorância, procurando diminuir a angústia de seus pacientes com ansiolíticos, calmantes ou qualquer outro medicamento, na melhor das hipóteses ineficazes para (o tratamento) da disfunção sexual”. É observável que, mesmo no campo científico, as pesquisas estão sujeitas à restrições em função dos tabus a que os sujeitos estão submetidos. Soma-se a isso o fato de que as universidades que formam psicólogos possuem com organizadores de seus programas curriculares profissionais que não despertaram uma real preocupação no tocante a esse tema, seja por desinformação ou por preconceitos. A partir dessa realidade, Kusnetzoff faz uma denúncia (dirigindo-se aos leitores): “... é mais provável que o leitor deste livro, ao terminar a leitura, saiba bastante mais sobre a sexualidade... que a imensa maioria dos profissionais médicos e psicólogos...”. Mais à frente ele continua: “... é dificil encontrar terapeutas adequados. A maior parte da população não está bem informada e, sobretudo, existe resistência ao tema. Os preconceitos sociais ganham a partida e a ignorância é a regra. Podemos imaginar, facilmente, como é o panorama aqui mesmo, na América Latina”. 
É notório que as universidades do Brasil têm como missão a formação de profissionais generalistas no campo da psicologia. Tal demanda parte da constatação de que os psicólogos recém-formados são levados a atuar em diversas áreas no campo da psicologia, atendendo, em sua maioria, indivíduos de baixo poder aquisitivo mediante convênios e militância profissional através de órgãos públicos e assistenciais.

Os centros de formação de psicólogos no Brasil possuem escassos recursos financeiros destinados à pesquisa. Por muito tempo os profissionais aqui gerados assumiram uma postura de mantenedores do "saber" estabelecido, mais do que de investigadores.

Felizmente, apesar desse quadro e dos "olhares desconfiados" de cientistas do comportamento humano que atuam no Brasil, herdeiros de posturas ortodoxas, germinam centros de estudos com propostas novas para uma questão tão antiga presente em todas as sociedades humanas: a difícil arte de viver com prazer a própria sexualidade. Como exemplo podemos citar o CESEX/Brasília, Instituto Cavalcanti/Belo Horizonte, Instituto H. Ellis/São Paulo, outros centros e um grande número de profissionais que individualmente desenvolvem pesquisas nesse campo, como podemos observar nos Congressos de Sexualidade e nas publicações que giram em torno desse tema.

Vivemos em meio a grandes transformações sociais que afetam radicalmente as relações entre os sexos. Podemos estar certos de que a questão dos transtornos da conduta sexual é de grande importância para a atuação do psicólogo clínico, sendo que a necessidade de se buscar melhores respostas ao problema, provavelmente, não se fará esgotar a curto prazo. Portanto precisamos no Brasil de profissionais que estejam preparados para atender a demanda de tais pacientes. Não podemos pensar simplesmente em indivíduos provenientes de "uma cultura brasileira", mas em indivíduos provenientes de "culturas brasileiras". Nosso compromisso não se restringe a um grupo especificamente, mas deve se estender a todos indiscriminadamente e neste momento é preciso estarmos prontos para lidar com grupos pouco favorecidos, em todos os níveis, que se tornaram portadores de mais uma "falta", a possibilidade de exercer de forma natural sua vida sexual. Se as pessoas não vivenciaram o "gozo" na vida sexual, sendo elas já pais ou mães, tomando como ponto de vista a questão da libido, podemos entender que tais indivíduos são assexuados. É necessário que se busque para a prática clínica uma parceria entre a etiologia e a atuação diretiva sobre o sintoma. No mínimo, é preciso que a sociedade possa contar com profissionais mais bem informados no tocante aos transtornos sexuais e mais atentos às demandas de seus pacientes. 


\section{REFERÊNCIAS BIBLIOGRÁFICAS}

1. BRENOT, P. (1994). La sexologie. Paris, Presses Universitaires de France.

2. CAVALCANTI \& CAVALCANTI, (1992). Tratamento clínico das disfunções sexuais. São Paulo, Roca.

3. DESPRATS-PÉQUIGNOT, C. (1992). La psychopathologie de la vie sexuelle. Paris, Presses Universitaires de France.

4. DIAS, C. (1996). Les troubles sexuels au Brésil et leurs rapports avec les problèmes dídentité. Amiens, Biblioteca da Université de Picardie Jules Verne.

5. DOR, J. (1993). Estruturas e clínica psicanalítica. Rio de Janeiro, Taurus.

6. EY, H. (1978). Tratado de psiquiatria. Barcelona, Toray-Masson.

7. FOUCAULT, M. (1976). Histoire de la sexualité -La volonté de savoir. Paris, Gallimard.

8. FREUD, S. (1908). Moral sexual civilizada a doença nervosa moderna, vol. IX. Rio de Janeiro, Imago, 1976.

9. FREUD, S. (1895). Sobre os critérios para destacar da neurastenia uma síndrome particular insulada "Neurose de Angústia", vol. III. Rio de Janeiro, Imago, 1976.

10. JEANNIÈRE, A. (1965). Antropologia sexual. Lisboa, Duas Cidades.

11. KAPLAN, H. 1. (1974). A nova terapia do sexo. Rio de Janeiro. Nova Fronteira, 1990.

12. KAPLAN, H. 1. (1994). Compêndio de psiquiatria: ciências do comportamento e psiquiatria clínica. Porto Alegre, Artes Médicas.

13. KUSNETZOFF, J. (1987). O homem sexualmente feliz. Rio de Janeiro. Nova Fronteira.

14. LIPIANSKY, E. (1992). Identíté et communication. Paris, Presses Universitaires de France.

15. LORENZI-CIOLDI, F. (1988). Individus dominants et groupes dominés. Grenoble, Presses Universitaires de France.

16. Ministério do Planejamento e Orçamento. Anuário Estatístico do Brasil. Rio de Janeiro. IBGE, 1994.

17. PEWZNER, É. (1992). L'homme coupable. Paris, Odile Jacob. 